\title{
FORMAÇÃO DE ENGENHEIROS PARA A INDÚSTRIA 4.0
}

\author{
Aline Eurich da Silva - eurichaline@ hotmail.com \\ Universidade Tecnológica Federal do Paraná \\ Rua Doutor Washington Subtil Chueire, 330 \\ 84017220 - Ponta Grossa - Paraná
}

Elis Regina Duarte - erduarte@utfpr.edu.br

Universidade Tecnológica Federal do Paraná

Rua Doutor Washington Subtil Chueire, 330

84017220 - Ponta Grossa - Paraná

Gabriela Guilow - gabrielaguilow @ gmail.com

Universidade Tecnológica Federal do Paraná

Rua Doutor Washington Subtil Chueire, 330

84017220 - Ponta Grossa - Paraná

Resumo: Com a recém Revolução Industrial 4.0 tornou-se necessária a atualização não somente dos meios de produção, mas também dos trabalhadores. Um novo perfil profissional vem revelando a necessidade de adquirir novas capacidades, para isso o seguinte projeto foi criado. Este projeto trata da importância da educação empreendedora ao relacionar problemas reais de uma indústria e a aptidão de desenvolver habilidades para a indústria 4.0. Em média quinze alunos de diferentes cursos participaram de encontros semanais para desenvolver novas competências, e ao final de cada dinâmica um formulário era respondido para análise do autodesenvolvimento dos participantes. Como resultado todos os acadêmicos que permaneceram até o fim do projeto relataram, através dos formulários, que puderam aperfeiçoar algumas competências técnicas e aprender novas habilidades subjetivas, como inovação, comunicação e trabalho em equipe.

Palavras-chave: Indústria 4.0. Engenharia. Educação empreendedora. Habilidades subjetivas. Habilidades técnicas.

\section{INTRODUÇÃO}

No decorrer dos últimos anos tem-se tornando perceptível a implementação de inovações na indústria, sendo estas reconhecidas como uma nova revolução industrial, ou seja, a Indústria 4.0. Com o surgimento dessa, há a necessidade de uma formação profissional que a contemple. Para isso inúmeras universidades têm aperfeiçoado seu sistema de ensino para formarem profissionais hábeis.

Ainda, com o advento dessas inovações a busca por perfis profissionais tem mudado. Capacidade de trabalhar em equipe, criatividade e comunicação são apenas algumas das exigências atuais para os profissionais 4.0. Diante dessa demanda há a necessidade de atualização por parte não somente dos próprios profissionais, mas também dos locais de ensino. As universidades precisam criar estratégias para despertar em seus alunos o espírito empreendedor, sendo estimulados por uma educação empreendedora. 
Para que o aluno se torne um solucionador é preciso utilizar novas formas de ensino que deem ao aluno a oportunidade de se deparar com problemas reais e buscar formas de resolver esses problemas. Ambientes repletos de trocas e processos dinâmicos de associação e aplicação são essenciais para formar novas habilidades.

Assim, o projeto "Desenvolvendo habilidades do Engenheiro 4.0 a partir de problemas ambientais da Indústria" tem como objetivo utilizar a educação empreendedora como ferramenta de aprendizagem no desenvolvimento de habilidades requeridas nos alunos de graduação em engenharia, para se tornarem um engenheiro 4.0. Isso através de ações que envolvam problemas reais da sociedade e indústrias na temática sustentabilidade.

\section{INDÚSTRIA 4.0}

Segundo Aires, Moreira e Freire (2017, p.8) a primeira revolução industrial (século XVIII até XIX) teve como característica o início do uso da máquina a vapor, tirando assim o aspecto artesanal da produção. Já a segunda revolução industrial (século XIX até XX) ocorre em paralelo ao início do uso da energia elétrica, possibilitando a aceleração do processo de produção. Ainda, a terceira revolução industrial, que iniciou a partir da segunda metade do século XX é marcada pela automatização dos processos.

De acordo com Lima e Pinto (2019, p.4), a quarta revolução industrial iniciou na primeira década do século XXI, e encontra-se em constante expansão. Sendo definida não somente pela automatização dos processos, mas também por conectar os âmbitos físicos, biológicos e digitais. Possibilita ainda uma comunicação instantânea de toda a cadeia produtiva, através do processo de digitalização, criando assim uma produção em massa customizada. Dessa forma é possível observar métodos mais eficientes, gerando maior velocidade e diversidade de produção, e consequentemente um maior lucro.

Assim, toda revolução industrial requer um novo perfil profissional, e na revolução 4.0 não é diferente. Uma indústria tão moderna requisita habilidades e conhecimentos nunca vistos, sendo necessária uma qualificação adequada dos trabalhadores para atuarem mediante a essas novas tecnologias.

\subsection{Habilidades do engenheiro na indústria 4.0}

Conforme já relatado, a indústria 4.0 exige um novo perfil de trabalhador. Alta capacidade de aprendizado, inovação, elevado conhecimento técnico, são algumas das exigências. Ainda, conforme sugerem as autoras Aires, Moreira e Freire, da Universidade Federal de Santa Catarina (UFSC), (2017, p.13):

Fica evidente que além do conhecimento técnico o profissional precisa saber colocar seu conhecimento em prática, solucionando problemas com criatividade e inovação, gerando valor para a organização em que está atuando, contribuindo para a construção da vantagem competitiva necessária para as organizações da quarta revolução industrial.

Bem como, os engenheiros são alguns dos profissionais que deverão desenvolver-se, aperfeiçoando suas habilidades subjetivas e competências técnicas. Sendo que a última pode ser aprendida e facilmente quantificada. Essas capacidades podem ser exemplificadas como certificados de cursos de graduação, proficiência em idiomas, programação, habilidades de escrita, entre outras. Assim como, podem ser escritas em currículos e facilmente comparáveis com as de outros candidatos. Os engenheiros costumam ter essas características mais acentuadas. 
Já as habilidades comportamentais podem ser relacionadas a personalidade das pessoas e a forma que o indivíduo interage com os demais, sendo assim são mais difíceis de quantificar e comparar. Como as habilidades subjetivas podem ser citadas: comunicação, liderança, trabalho em equipe, percepção de urgência, proatividade, capacidade de tomar decisões, criatividade, visão geral, capacidade de resolver problemas e relacionamento interpessoal. São mais difíceis de serem observadas e desenvolvidas, porém a atual demanda da indústria acaba tornando necessário o desenvolvimento dessas habilidades nas formações de novos engenheiros. Assim, torna-se fundamental a realização de atividades que explorem e desenvolvam as habilidades anteriormente citadas.

\subsection{Educação empreendedora}

Quando se iniciou o ensino do empreendedorismo há mais de 70 anos nos Estados Unidos, o intuito era formar acadêmicos capazes de administrar empresas. Mas ao passar dos anos notou-se a necessidade de explorar o tema inovação, agregando maior criatividade e poder de inovação aos estudantes. Deste modo o empreendedorismo aliado a inovação tem permitido o autodesenvolvimento dos alunos, e construído uma nova visão da economia e da sociedade.

Assim, para acompanhar as evoluções da sociedade e proporcionar uma formação plena aos estudantes, uma nova forma de ensino tem sido adotada, a educação empreendedora. Esta é esclarecida por Filion (1999, p.11):

[...] por ser calcar mais na atividade do próprio aluno, numa forma mais experimental, mais prática e contextualizada no mundo real e que prepara o indivíduo para lidar com as incertezas, a falta de recursos e a indiferenciação típica do início de uma organização/iniciativa. E que incentiva a imaginação e a análise. (apud LOPES, 2010, p. 28).

Sendo assim, para o desenvolvimento dessas habilidades é necessário que os alunos entrem em contato com um ambiente de aprendizagem diferente do tradicional, onde devem ser realizadas metodologias de aprendizagem que se diferenciam das clássicas. Um ambiente que alinhe a teoria à prática encontrada nas indústrias.

Ainda, dentre as novas metodologias de aprendizagem pode-se destacar a Aprendizagem Baseada em problemas (ABP) ou "Project-Based Learning (PBL)", onde nesse método é oferecido aos alunos um meio para adquirir novos conhecimentos e desenvolver as habilidades necessárias para a indústria 4.0. Segundo Masson et al. (2012) essa metodologia deu-se início em 1900 com o filósofo John Dewey que comprovou o "aprender mediante fazer", assim valorizando a capacidade de pensamento dos alunos. Dessa forma os alunos gradualmente adquirem conhecimentos relativos a problemas reais.

\subsection{O projeto "Desenvolvendo as habilidades do engenheiro da indústria 4.0 a partir de problemas ambientais da indústria"}

Conforme já descrito acima, a atual conjuntura industrial requer engenheiros habilidosos para trabalharem em empresas inovadoras. Para isso, muitas universidades vêm atualizando suas formas de ensino para preencherem essas demandas do profissional 4.0. Entre elas, encontra-se a Universidade Tecnológica Federal do Paraná, campus Ponta Grossa, que vem proporcionando através de projetos de extensão o aperfeiçoamento dos acadêmicos para o mundo profissional moderno. Entre esses programas tem-se o projeto "Desenvolvendo habilidades do Engenheiro 4.0 a partir de problemas ambientais da Indústria", que tem como intuito fomentar o lado profissional dos alunos que participam, ao propor dinâmicas e oficinas de resolução de problemas ambientais encontrados em diversas empresas. Esse projeto conta 
com uma professora orientadora e uma aluna bolsista na organização das atividades do projeto.

Assim, para melhor apresentar as habilidades desenvolvidas durantes alguns encontros realizados durante o semestre, foi criada o seguinte quadro onde é possível visualizar os objetivos de cada atividade e as habilidades subjetivas e técnicas trabalhadas.

Quadro 1 - Atividades e dinâmicas realizadas e as respectivas habilidades desenvolvidas

\begin{tabular}{|c|c|c|c|}
\hline Encontro & Objetivos do encontro & Atividades realizadas & Habilidades desenvolvidas \\
\hline \multirow{2}{*}{$\begin{array}{l}\text { Primeira encontro } \\
\text { entre os participantes }\end{array}$} & $\begin{array}{l}\text { Permitir que os participantes } \\
\text { pudessem conhecer seus colegas e ter } \\
\text { uma visão geral do projeto }\end{array}$ & $\begin{array}{c}\text { Desenho que } \\
\text { representasse suas } \\
\text { expectativas para com o } \\
\text { projeto }\end{array}$ & Criatividade e inovação \\
\hline & $\begin{array}{l}\text { Observar melhor as situações e ter } \\
\text { capacidade de olhar as coisas de } \\
\text { forma mais simples }\end{array}$ & "Dinâmica da colher" & $\begin{array}{l}\text { Comunicação, capacidade de } \\
\text { tomar decisões, criatividade, } \\
\text { trabalho em equipe, visão geral, } \\
\text { relacionamente interpessoal }\end{array}$ \\
\hline $\begin{array}{l}\text { Encontro de } \\
\text { introdução aos casos } \\
\text { de problemas } \\
\text { ambientais }\end{array}$ & $\begin{array}{l}\text { Visualizar atráves de vídeos como são } \\
\text { os problemas ambientais das } \\
\text { indústrias e pensar de forma macro e } \\
\text { usando da engenharia } 4.0 \text { para } \\
\text { encontrar possiveis soluções }\end{array}$ & "Dinâmica do envelope" & $\begin{array}{c}\text { Comunicação, liderança, } \\
\text { proatividade, capacidade de tomar } \\
\text { decisões, criatividade, trabalho } \\
\text { em equipe, visão geral, } \\
\text { capacidade de resolver problemas } \\
\text { e relacionamente interpessoal }\end{array}$ \\
\hline \multirow[b]{2}{*}{$\begin{array}{l}\text { Encontro para } \\
\text { formação de equipes }\end{array}$} & $\begin{array}{c}\text { Aprender sobre apresentações orais e } \\
\text { normativas técnicas }\end{array}$ & $\begin{array}{l}\text { Participante apresentou a } \\
\text { NBR } 5462\end{array}$ & $\begin{array}{c}\text { Capacidade de aprendizagem, } \\
\text { criatividade, comunicação, } \\
\text { aprendizagem ativa e escuta ativa }\end{array}$ \\
\hline & $\begin{array}{c}\text { Gerar a habilidade de trabalho em } \\
\text { equipe e capacidade de resolução de } \\
\text { problemas ambientais }\end{array}$ & $\begin{array}{l}\text { Para a resolução dos } \\
\text { problemas dados } \\
\text { formaram-se equipes } \\
\text { multidiciplinares }\end{array}$ & $\begin{array}{l}\text { Analisar e resolver problemas; } \\
\text { comunicação; inovação; } \\
\text { conhecimento técnico; capacidade } \\
\text { de interação com outras áreas do } \\
\text { conhecimento; coordenação de } \\
\text { equipe; inteligência emocional; } \\
\text { negociação; tomada de decisão }\end{array}$ \\
\hline $\begin{array}{l}\text { Encontro de } \\
\text { percepções }\end{array}$ & $\begin{array}{l}\text { Desenvolver habilidades de } \\
\text { comunicação e criatividade ao usar } \\
\text { das percepções visuais e da escuta }\end{array}$ & $\begin{array}{l}\text { "Dinâmica História X } \\
\text { Estória" }\end{array}$ & $\begin{array}{l}\text { Comunicação, capacidade de } \\
\text { tomar decisões, criatividade, } \\
\text { trabalho em equipe, visão geral, } \\
\text { relacionamente interpessoal }\end{array}$ \\
\hline
\end{tabular}

Fonte: dados da pesquisa

Ademais, como parte do projeto os acadêmicos foram desafiados com três casos de problemas ambientais encontrados em indústrias. Cada equipe era responsável por resolver esses problemas à medida que novas informações chegavam. Ainda, dentro das equipes os alunos estudaram mais sobre os temas de cada caso em busca de soluções, sempre realizando apresentações explicando seus exemplos e as possíveis soluções encontradas. Assim, após alguns encontros as equipes foram mescladas tornando-as multidisciplinares, e por fim todos os participantes uniram-se para encontrar as soluções para os casos dados. A seguir estão algumas informações dos casos estudados:

1-) Caso de uma indústria onde o prédio sofria com restrição de água para atender a demanda dos funcionários, da refrigeração e do resfriamento, sendo necessário em média $1800 \mathrm{~m}^{3}$ de água por mês. Sendo sugerido coletar água pluvial e tratar efluentes, diminuindo a dependência da concessionária de água.

2-) Caso de uma indústria de abate bovino que tinha problemas com a geração de poluentes após a digestão de subprodutos. Foi sugerido aos alunos trabalhar com lavador de 


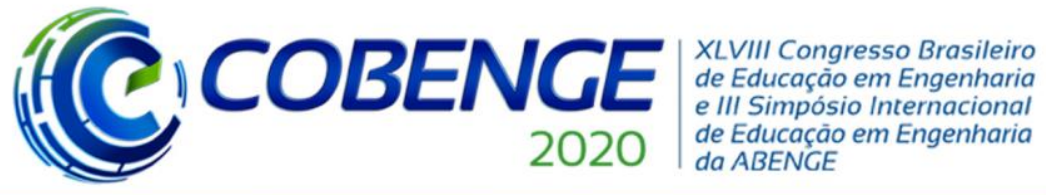

"Os desafios para formar hoje o engenheiro do amanhã"

gases, fornalha ou biofiltro. Também foi explicado que esses equipamentos possuem problemas e falhas.

3-) Tratamento de efluentes com resíduo tóxico. Sendo aconselhado aos participantes tornar o nitrito (tóxico) em reagente limitante, isso ao controlar $\mathrm{pH}$ e manter a taxa de oxigênio na água alta.

Ainda, sobre o trabalho em equipe os participantes relataram que foi uma excelente experiência. Houve troca de conhecimentos e a percepção de como as pessoas veem problemas de formas diferentes, contribuindo para encontrar a melhor solução.

Com atividades diferentes das clássicas que costumam ser realizadas em sala de aula os alunos conseguem desenvolver habilidades subjetivas e se relacionar melhor com o professor e seus colegas. Pois é proporcionado ao aluno a oportunidade de desenvolver melhor sua personalidade e sua relação com os demais, tornando-o mais independente em seu aprendizado e empreendedor do próprio conhecimento.

Por fim, o projeto foi apresentado para alunos ingressantes nos cursos da UTFPR em 2020/1 onde foi ensinado sobre indústria 4.0 e aplicado uma dinâmica para ensinar os alunos a importância de saberem lidar com seus colegas além de rótulos de aparência. Em 2020 o projeto retornou como uma disciplina optativa dentro do curso de Engenharia de Bioprocessos e Biotecnologia, onde foi realizado a dinâmica da colher e os alunos notaram que puderam desenvolver diversas habilidades.

\section{RESULTADOS}

Gráfico 1: “Já havia estudado anteriormente sobre indústria 4.0?”

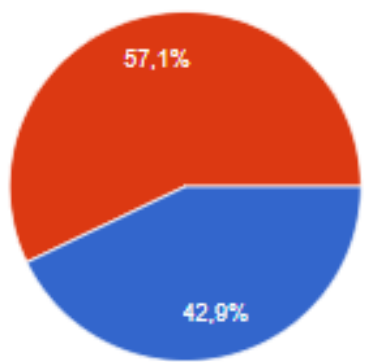

Sim

- Nåo

Fonte: dados da pesquisa

Ao questionar os acadêmicos participantes se já haviam estudado sobre indústria 4.0 foi possível observar que $57,1 \%$, conforme Gráfico 1 , nunca haviam estudado esse tema. Assim uma maioria não está familiarizada com o termo indústria 4.0 que é de extrema relevância para os futuros profissionais da indústria.

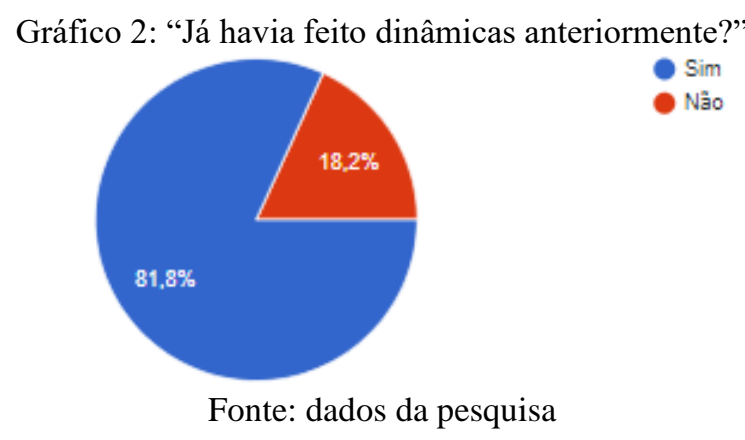




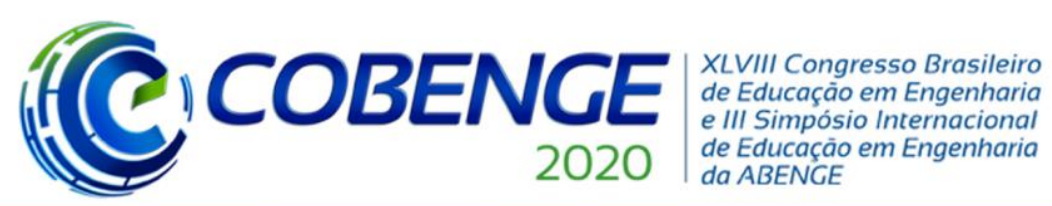

"Os desafios para formar hoje o engenheiro do amanhã"
$\mathrm{Ol}$ a $\mathrm{O} 3$ de dezembro Evento On-line

Gráfico 6: "Qual habilidade soft skill você acredita ter sido desenvolvida na dinâmica do envelope?"

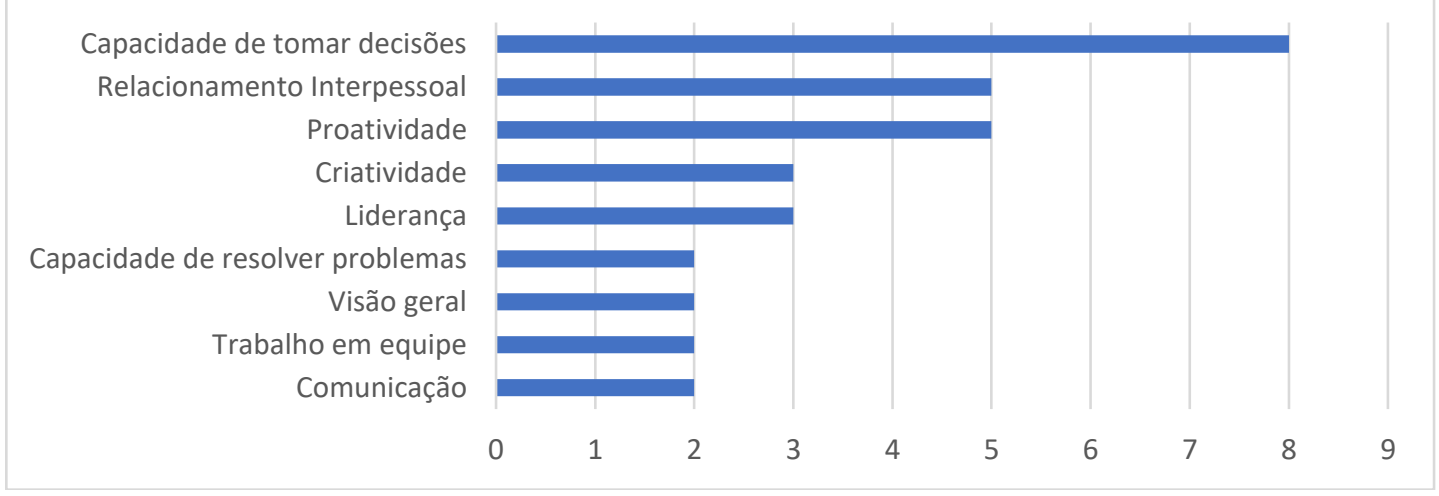

Fonte: dados da pesquisa

Nos Gráficos 3, 4, 5 e 6 podemos observar quais competências foram desenvolvidas ou não em cada uma das dinâmicas realizadas durante o projeto. Ficando evidente que as dinâmicas da torre e do envelope foram as responsáveis por um maior desenvolvimentos das habilidades nos participantes.

Gráfico 7: "Você acredita que uma equipe multidisciplinar auxiliou na solução do problema?"

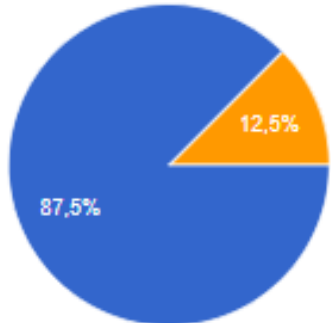

Sim

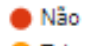

Fonte: dados da pesquisa

Conforme o Gráfico 7, 87,5 \% dos alunos acredita que a formação de uma equipe multidisciplinar auxiliou na resolução dos casos. Evidenciando assim a importância de o aluno adquirir conhecimentos diversos, pois uma formação multidisciplinar o auxilia na resolução de problemas reais da indústria na função de engenheiro.

Gráfico 8: "Indique três habilidades do engenheiro 4.0 que você acredita ter desenvolvido"

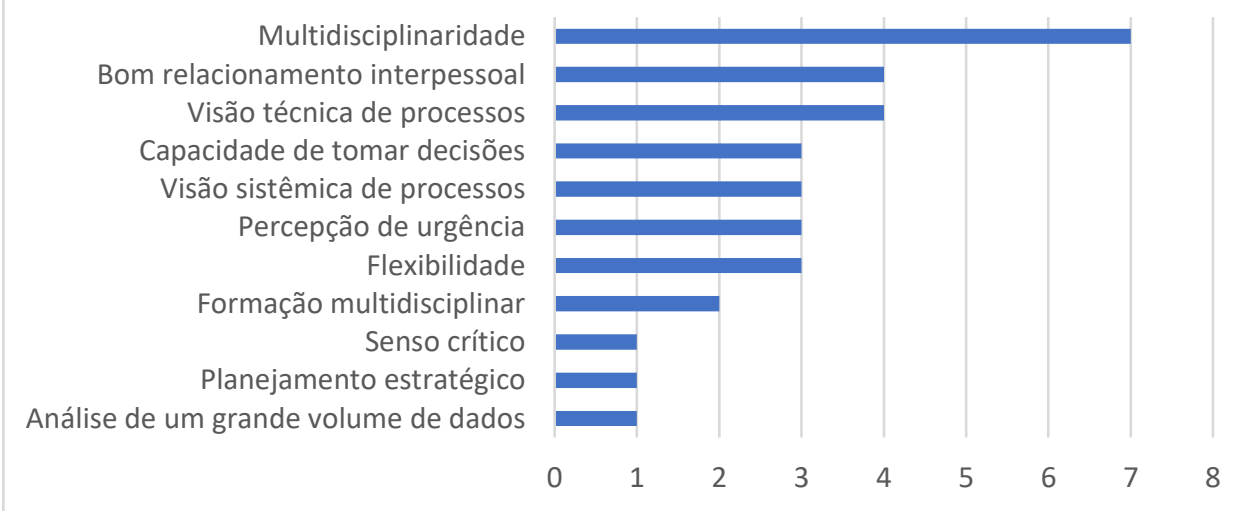

Fonte: dados da pesquisa 
O Gráfico 8 retrata as habilidades que os alunos acreditam ter desenvolvido após o fim do primeiro semestre do projeto, sendo a habilidade mais citada a de multidisciplinaridade. Mostrando então a importância da participação de alunos de diversos cursos de engenharia, havendo assim a aquisição de conhecimentos diferentes do que são comuns para sua área de estudos. Em um mesmo caso os alunos precisavam utilizar biotecnologia, química, mecânica e elétrica, tendo que aprender sobre aquilo que não dominam e integrar com os conhecimentos já adquiridos.

Em relação aos casos fornecidos, a primeira equipe encontrou a solução de utilizar um reservatório para armazenar a água da chuva com sensor que definiria quando deveria ser utilizada a água do reservatório e quando deveria ser utilizada a água da fornecedora de água. Já a segunda equipe encontrou a solução de unir um biofiltro com um lavador de gases, porque assim a área ocupada pelo biofiltro seria menor. Sendo necessário também escolher um ou mais microrganismos que sejam apropriados para degradação dos produtos, e por fim adicionar os nutrientes para estes microrganismos utilizados no biofiltro. E em relação ao terceiro caso, o grupo optou por utilizar dois reatores, sendo o primeiro responsável na oxidação da amônia passando para nitrato. Já no segundo reator utiliza-se bactérias nitrificantes que transformam o nitrato em nitrito, e por fim este passa para nitrogênio gasoso.

\section{CONSIDERAÇÕES FINAIS}

Com esse trabalho podemos concluir que o atual modelo industrial necessita de profissionais que possuem determinadas competências para suprir suas demandas, sendo papel das universidades e institutos de ensino preparar os futuros trabalhadores para esse mercado de trabalho. Porém tem se mostrado um desafio as instituições elaborarem atividades que fujam das clássicas, e que permitam o desenvolvimento das habilidades profissionais solicitadas. As soluções encontradas tem sido aplicar atividades como dinâmicas, apresentações, pesquisas e resoluções de casos. Sendo excelentes formas de ampliar as habilidades subjetivas relacionadas ao psicológico dos alunos, e instigando em cada um o espírito empreendedor do próprio aprendizado. Essas habilidades vão tornar o acadêmico de engenharia mais capacitado para atender as necessidades da indústria, obtendo uma visão geral das situações e apto a resolver problemas complexos.

\section{Agradecimentos}

O presente trabalho foi realizado com o apoio da Universidade Tecnológica Federal do Paraná - UTFPR. Agradecemos a Universidade Tecnológica Federal do Paraná- UTFPR pela bolsa concedida.

\section{REFERÊNCIAS}

AIRES, Regina Wundrack do Amaral; MOREIRA, Fernanda Kempner; FREIRE, Patricia de Sá. Indústria 4.0: Competências requeridas aos profissionais da Quarta Revolução Industrial. In: Anais do VII Congresso Internacional de Conhecimento e Inovação, Foz do Iguaçu, 2017.

DE LIMA, Alison Gustavo; PINTO, Giuliano Scombatti. INDÚSTRIA 4.0. Revista Interface Tecnológica, v. 16, n. 2, p. 299-311, 2019. 
"Os desafios para formar hoje o engenheiro do amanhã"

FILION, Louis Jacques. Empreendedorismo: empreendedores e proprietários-gerentes de pequenos negócios. Revista de Administração da Universidade de São Paulo. São Paulo,v.34,n.2,p.05-28,abril/junho, 1999.

LAKER, Dennis R.; POWELL, Jimmy L. The differences between hard and soft skills and their relative impact on training transfer. Human resource development quarterly, v. 22, n. 1, p. 111-122, 2011.

LOPES, Rose Mary A.. Educação Empreendedora. Rio de Janeiro: Elvesier, 2010.

MASSON, Terezinha Jocelen et al. Metodologia de ensino: aprendizagem baseada em projetos (pbl). In: Anais do XL Congresso Brasileiro de Educação em Engenharia (COBENGE), Belém, 2012. p. 13.

MUCHACHO, Filipa D. et al. Autopercepção das soft e hard skills em estudantes universitários: o papel dos traços de personalidade e da área de curso. 2019. Tese de Doutorado. Disponível em: < http://hdl.handle.net/10400.12/7157 >. Acesso em: 5 jun. 2020.

SILVA, Carlos Manuel Mendes da. Estudo das competências pessoais e interpessoais de acordo com as soft skills e hard skills nos empresários das PMEs. 2012. Dissertação de Mestrado. Disponível em: < https://recil.grupolusofona.pt/handle/10437/4051 >. Acesso em: 10 jun. 2020.

VOLPE, Waini et al. Análise dos cursos de engenharia de produção no contexto de formação dos engenheiros para o ambiente da Indústria 4.0: Analysis of the courses of industrial engineering in the context of training of engineers for the industry 4.0 environment. 2019.

\title{
ENGINEER TRAINING FOR INDUSTRY 4.0
}

\begin{abstract}
With the recent Industrial Revolution 4.0, it was necessary to update not only the means of production but also the workers. A new professional profile has revealed the need to acquire new skills, for which the following project was created. This project deals with the importance of entrepreneurial education in relating real problems in an industry and the ability to develop skills for industry 4.0. On average, fifteen students from different courses participated in weekly meetings to develop new skills, and at the end of each dynamic, a form was answered to analyze the participants' self-development. As a result, all the academics who stayed until the end of the project reported, through the forms, that they could improve some hard skills and learn new soft skills, such as innovation, communication and teamwork.
\end{abstract}

Keywords: Industry 4.0. Engineering. Entrepreneurial education. Soft skills. Hard skills. 